\title{
Properties and clinical application safety of antibiotic-loaded bone cement in kyphoplasty
}

\author{
Maciej Opalko ${ }^{1}$, Hans Bösebeck ${ }^{2^{*}}$ (D) and Sebastian Vogt ${ }^{3}$
}

\begin{abstract}
Background: Evidence on antibiotic-loaded bone cement remains too vague to guide kyphoplasty in patient care. We clinically evaluated the properties and benefits of a new low viscosity polymethylmethacrylate (PMMA) bone cement loaded with gentamicin.
\end{abstract}

Methods: In this non-randomised, monocentric, prospective open trial, 50 consecutively enrolled patients with fractures of the vertebral body (TH7-L4) due to osteoporosis or trauma were investigated between 2010 and 2013, with a 1-year post-op follow-up per patient. The antibiotic-loaded PMMA bone cement was administered to patients during the surgery according to the standard procedure established on site for one-staged kyphoplasty. The clinical outcome was assessed according to function and pain by standardised anamnesis, clinical investigation, validated visual analogue scale (VAS) vertebral spine score, Oswestry Low-Back-Pain (ODI) Disability score, and Short Form (SF)-36 score. We further performed $\mathrm{X}$-ray and magnetic resonance imaging with radiomorphometric assessment.

Results: The patients showed beneficial effects concerning low back pain disability (mean ODI score; screening, $68.0 \pm$ $15.8 \%$ vs month 12,42.8 $\pm 24.5 \%$ ). The pain level was decreased (VAS vertebral spine score; screening, $68.8 \pm 17.6$ vs month $12,43.8 \pm 22.2$ ) and the general health state was improved (SF-36; especially 'role limitations due to emotional problems' ( $51.9 \pm 44.7$; month 6), followed by 'role limitations due to physical health' (36.1 \pm 42.4 ; month 6), and 'pain' (34.6 \pm 35.3 ; month 6)). No vertebral infection did occur during the hospital stay or the 1-year follow-up. The stabilisation and restoration of the fractured bodies were radiologically confirmed. A reduced rate of leakage was observed, combined with a decreased risk of infection and an improved patient safety after a 1-year follow-up period.

Conclusion: Requirements for bone cement in a kyphoplasty setting were excellently fulfilled. Application technique and cement properties may influence the success of the surgery.

Trial registration: Deutsche Institut für Medizinische Dokumentation und Information (DIMDI), HM-KS-0901, Registered 14 September 2009, https://www.dimdi.de/dynamic/de/medizinprodukte/datenbankrecherche/

Keywords: Antibiotic-loaded bone cement (ALBC), Local antibiotic treatment, Kyphoplasty, Gentamicin, Osteopal G, Low viscosity cement, PMMA

\footnotetext{
* Correspondence: hans.boesebeck@heraeus.com

${ }^{2}$ Heraeus Medical GmbH, Medical Affairs, Philipp-Reis-Str. 8/13, 61273

Wehrheim, Germany

Full list of author information is available at the end of the article
}

(c) The Author(s). 2019 Open Access This article is distributed under the terms of the Creative Commons Attribution 4.0 International License (http://creativecommons.org/licenses/by/4.0/), which permits unrestricted use, distribution, and reproduction in any medium, provided you give appropriate credit to the original author(s) and the source, provide a link to the Creative Commons license, and indicate if changes were made. The Creative Commons Public Domain Dedication waiver (http://creativecommons.org/publicdomain/zero/1.0/) applies to the data made available in this article, unless otherwise stated. 


\section{Background}

Fractures of the vertebral body have a prevalence of approximately $10-15 \%$ in patients over 50 years of age. They may be treated by a vertebroplasty and/or kyphoplasty as accepted procedures in this clinical setting [1-3]. Kyphoplasty provides a minimally invasive method for the stabilisation of fractured vertebral bodies with the largest extent of decompression through a balloon system. The technique has been widely used since the year 2000 [4]. Compared to vertebroplasty [5], kyphoplasty shows benefits regarding the quality of life [6] and reveals an equal or improved efficacy in restoring the mechanical function after severe vertebral wedge fractures.

However, along with an increase in the total number of kyphoplasties, the rate of infections after the application of cement has increased as well [7]. Spondylitis caused by foreign bodies appears to be a severe complication in this group of patients [8]. Recent experience with hip endoprosthesis has shown that adding the antibiotic gentamicin [9] to the bone cement used during the surgery is an appropriate approach to decrease the rate of perioperative infections [10]. Such an effect can also be expected in kyphoplasty when using a gentamicin-loaded cement with proper handling characteristics, including an adequate working phase with constant viscosity. Furthermore, a comparable or better rate of cement leakage [11, 12], pain reduction, and a radiologically confirmed reconstruction of the height of the vertebral body may be achieved in kyphoplasty by using a gentamicinloaded cement with suitable viscosity.

The use of antibiotic-loaded bone cement (ALBC) for the treatment of fractures of the vertebral body in a kyphoplasty setting is currently not well supported by evidence through literature [13]. Key questions in dealing with ALBCs are a better understanding of the cement properties, application benefits, and safety for clinical use. To overcome this lack of information, prospective trials with ALBCs are needed to investigate both efficacy and risk.

The primary objective of this prospective clinical trial was to observe the properties of a low-viscosity, antibiotic-loaded bone cement in a kyphoplasty setting. Secondary objectives were clinical outcome, application safety, and influence of the administered cement on the success of the surgery [1].

\section{Materials and methods Study design}

We clinically evaluated properties and benefits of a new low viscosity polymethylmethacrylate (PMMA) bone cement loaded with gentamicin in a non-randomised, monocentric, prospective open trial conducted in a German centre from 2010 to 2013. In total, 50 patients undergoing a one-staged kyphoplasty were enrolled. As there was no control group, only descriptive statistical methods were used.

\section{Patient population}

The trial population comprised of male or female patients of at least 50 years of age. In total, 50 patients with fractures of the vertebral body (TH7-L4) due to osteoporosis [14] or a trauma scheduled for one-staged kyphoplasty were consecutively screened and enrolled, and 49 were included in the safety population (SAF population). Exclusion criteria were known hypersensibility against ingredients of the tested bone cement, concomitant systemic gentamicin treatment, any concomitant disease (excluding a minimally invasive kyphoplasty of the vertebral body), presence of spondylitis or infection, renal impairment, sensorineural hearing loss, and hemorrhagic diathesis.

All patients who fulfilled the inclusion and exclusion criteria gave their written consent to participate. The trial duration per patient consisted of a screening period up to 7 days before the surgery, a hospitalisation period of 1 week including final examination, and a follow-up period of 12 months. The trial comprised ten clinical visits.

\section{Study intervention}

The investigational medical product (IMD) was administered to patients during the surgery according to the standard procedure established on site for one-staged kyphoplasty [15]. The antibiotic-loaded bone cement consists of two components-a powder and a fluid-and was mixed directly before use (Osteopal G, Heraeus Medical GmbH, Wehrheim, Germany) [16, 17]. The powder contained $0.325 \mathrm{~g}$ gentamicin per $26.5 \mathrm{~g}$ pouch of bone cement, and the fluid consisted of methyl methacrylate, dimethyl-p-toluidine, hydroquinone, and colorant E 141 in an ampoule of $10 \mathrm{ml}$. It was applied intraoperatively for minimal invasive kyphoplasty. The right time for the application was governed through the cement polymerization status. Depending on the need for kyphoplasty bone void filling of the vertebral body after fractures, the dosage was selected with usually $3 \mathrm{ml}$ bone cement per level. It was administered as a single intraoperative injection.

Radiomorphometric evaluations of native two-level Xray images were performed by two independent clinicians using six landmarks to determine the following medical parameters: the angle of kyphosis-the angle between two tangents attached to the ground and endplate of the radiological sagittal parameters of the spine-and the vertebral body index - the quotient of height of leading and rear edge and the pre- and post-operative height of the centre of the vertebral body (in \%). As a reference $(100 \%)$, the median height of an adjacent non-fractured vertebral body was used.

\section{Study measures}

The primary endpoints were the evaluation of the function by pain scores such as the visual analogue scale 
(VAS) vertebral spine score [18], the Oswestry-LowBack-Pain-Disability (ODI) score [19], and the Short Form (SF)-36 Health Status Query [20]. They were measured at up to 7 days before the surgery, during the final examination on day 6 , and at 6 and 12 months after the surgery. The radiological examination comprised twolevel X-ray-radiographs before the surgery, on the day of the surgery, and during the final examination as well as during the follow-ups at 6 and 12 months and magnetic resonance imaging radiomorphometry [21] of the augmented region preoperatively. All radiological examinations were carried out in lying positions. Furthermore, the cement leakage and the corresponding location were evaluated. Secondary outcomes included the intra- and post-operative assessment of the cement properties such as end of adhesiveness, working time, curing time at the time of and after the application, and the assessment of the amount of injected cement as well as its overall tolerability [22]. In this context, other investigation criteria included the amount of injected cement, imaging and visibility of the cement, the optimal injection pressure, and the complete duration of the surgical procedure.

The overall efficacy was assessed by the clinical investigator and the patients by evidences for a kyphoplasty related infection and a revision of the relevant spine level. The safety of the IMD was evaluated regarding its overall tolerability, the registration of events, and the Xray diagnosis. Fracture characteristics, vertebral body status, and clinical examinations have been performed.

\section{Statistics}

Only descriptive statistical methods were used in the present trial as there was no control group. Continuous parameters are presented with their means, standard deviations (SDs), medians, first and third quartiles, and minimum and maximum values. Frequencies were calculated for categorical variables. The descriptive summary statistics are presented for continuous baseline data (e.g. age, height) at screening as well as for categorical data (e.g. gender, ethnic origin, nicotine consumption, alcohol consumption, special diet, and reason of fracture). In addition, fracture characteristics and vertebral body status were investigated.

Since no specific hypothesis was tested, no formal calculation of sample size was performed.

The descriptive summary statistics at screening, day 6 post-op, month 6 post-op, and month 12 post-op are presented for the overall VAS vertebral spine score, the ODI score, and for the 8 dimensions of the SF-36 Health Status Query. Additionally, pre- and post-differences (value at post-op visit-screening value) were investigated. The parameters assessed by a radiomorphometric evaluation and two-level X-ray images (angle of kyphosis and vertebral body index) at surgery, day 6 post-op, month 6 post-op, and month 12 post-op were summarised in the scope of descriptive statistics. Mean values of the clinical and radiological parameters during the follow-up were compared to the screening ( $t$ test); $p$ values and $95 \%$ confidence intervals (CI) are given.

A shift analysis was performed on the cement leakage at surgery and day 6 post-op and to evaluate the overall tolerability at day 6 , month 6 , and month 12 post-op. The number and percentage of patients are given for the cement properties. All of the summary statistics are presented in order to assess the cement application procedure by evaluating the needle depth, needle volume, duration of intervention, and time frames of cement application. The number and percentage of patients are reported for the detectability of applied cement via X-ray at surgery, at month 6 , and at month 12 post-op.

The overall efficacy was evaluated by the variables 'any evidence for a kyphoplasty related infection' and 'had a revision of the relevant spinal level to be performed' was assessed by means of shift tables for each of these two parameters at visits day 6 , month 6 , and month 12 postop. For the additional secondary efficacy variable 'BOS', the number and percentage of patients are presented at the screening, at day 6 , month 6 , and month 12 post-op.

The AEs were reported by the investigators and provided in summary incidence tables for all reported AEs. The different proportions of the patients reporting the different AEs and SUEs, and treatment-related AEs were tabulated.

Summary statistics for vital signs and changes from the hospitalisation visit is displayed for all visits. The ECG results at screening and day 6 post-op (final examination) and the results of the physical examination as judged by the investigator were analysed using a shift table. Specifications of clinically relevant results by patient are given in an individual patient data listing. The number and percentage of patients who were still in hospital after the operation are reported by visit (day 4 , day 5 , and day 6 ).

Other analysis included previous and concomitant medications, anaesthetic and post-operative medications, number and percentage of patients who experienced any disease and underwent any previous surgery of the vertebral spine, and any complication in a previous vertebral spine intervention are shown.

All evaluations are provided for the SAF population.

\section{Results}

In total, 19 of the 50 patients enrolled (38.8\%) suffered from a fracture due to osteoporosis and 30 patients (61.2\%) due to a trauma. The most frequently documented fracture level was 'T12' (14 fractures [26.4\%]), followed by 'L1' (10 fractures [18.9\%]) and 'L2' (9 fractures $[17.0 \%])$. The grade of the fracture was classified according to Genant et al. [23] and AO Spine 
classification [24]; it was mainly 'mild' and 'moderate' (24 fractures [45.3\%] and 26 fractures [49.1\%], respectively). Most of the fractures had a 'wedge' morphology (24 fractures [45.3\%]). The age of the fracture ranged from 0 to 9 months with a mean of $0.7 \pm 1.6$ months. Regarding the vertebral body status, 'any rear edge involvement' was reported for most of the patients (23 patients [46.9\%]), followed by 'any vacuum phenomenon' (11 patients [22.4\%]).

The preoperative angle of kyphosis was $9.49^{\circ} \pm 6.17$ and was statistically significantly improved postoperatively $\left(4.14^{\circ} \pm 3.25 ; p \leq 0.0001 ; 95 \%\right.$ CI $\left.3.74,6.95\right)$ and at follow-up after 12 months $\left(6.76^{\circ} \pm 4.05 ; p=0.01 ; 95 \%\right.$ CI $0.7,5.1)$. Compared to preoperative $\left(0.8^{\circ} \pm 0.23\right)$, the postoperative vertebra body index differed statistically significant $\left(0.91^{\circ} \pm 0.08 ; p \leq 0.005 ; 95 \% \mathrm{CI}-0.17\right.$, $0.05)$. The difference was not statistically significant after 12 months follow-up $\left(0.86^{\circ} \pm 0.1 ; p \leq 0.1826 ; 95 \% \mathrm{CI}-\right.$ $0.14,-0.03)$.

\section{Patient characteristics}

The vast majority of patients had a medical history (47 patients [95.9\%]). For three patients (6.1\%), previous surgery of the vertebral spine was documented. In addition, one patient (2\%) had a complication at a previous surgery of the vertebral spine. Physical examination, investigation of the vital signs, and ECG were performed and documented together with the baseline laboratory data. All 49 patients of the SAF population took non-anaesthetics prior or concomitant medication, whereas the most frequent were 'analgesics' (43 patients [87.8\%]), followed by 'antithrombotic agents' (42 patients [85.7\%]) and 'agents acting on the reninangiotensin system' (32 patients [65.3\%]). The SAF population also took anaesthetics after the surgery and postoperative medication. Frequent anaesthetics and postoperative medications included 'muscle relaxants' (48 patients [98\%]) and 'antibacterials for systemic use' (35 patients [71.4\%]).

\section{Treatment and cement properties}

Before the surgery, a mean value for angle of kyphosis of $9.5 \pm 6.2^{\circ}$ was revealed. After the surgery, smaller values were measured: $4.1 \pm 3.3^{\circ}$ at day $0,6.2$ $\pm 3.5^{\circ}$ at day $6,7.2 \pm 4.8^{\circ}$ at month 6 , and $6.8 \pm 4.1^{\circ}$ at month 12. Higher mean values of the vertebral index were shown after the surgery compared to the preoperative values $(0.8 \pm 0.2$ at day 0 pre-op, $0.9 \pm$ 0.1 at day 0 post-op, $0.9 \pm 0.1$ at day $6,0.9 \pm 0.1$ at month 6 , and $0.9 \pm 0.1$ at month 12). For both parameters, the best results were revealed directly after the surgery. The results of the radiological investigation (Fig. 1) indicate an immediate and persisting stabilisation of the fractured vertebral bodies.
A mean value of $20.3 \pm 1.2^{\circ} \mathrm{C}$ for temperature in the operation theatre as well as the temperature of cement ready to use was revealed as this influences the success of the surgery as well [22]. The mean working duration was $4.4 \pm 2.0 \mathrm{~min}$. The mean balloon insufflation volume was $3.4 \pm 0.9 \mathrm{ml}$ on the left side and $3.3 \pm 0.8 \mathrm{ml}$ on the right side. For the majority of patients (28 patients [57.1\%]), the overall assessment of cement properties was 'good' (Table 1). An 'excellent' overall assessment was documented for 21 patients (42.9\%). The cement mixing procedure was assessed as 'good' for the vast majority of patients (45 patients [91.8\%]).

Figure 2 depicts the tests applied for pre- and perioperative monitoring of the cement.

Table 2 shows the evaluation of the timeframes for the cement application with a specific focus on the time of plasticity.

\section{Cement leakage and detectability}

Cement leakage was only documented for one patient (patient no. 4). This patient had a ventral right-sided cement leakage of $0.6 \mathrm{ccm}$ at surgery and at day 6 . The time of leakage for the one patient with cement leakage during surgery at the right side was $9.0 \mathrm{~min}$ (Table 2).

The X-ray revealed an excellent detectability of the applied cement investigated for the vast majority of patients at surgery and day 6 (47 patients [95.9\%] and 40 patients [81.6\%], respectively). The detectability was even excellent for the majority of patients ( 25 patients [51.0\%] and 32 patients [65.3\%], respectively) at month 6 and month 12.

\section{Main treatment effects}

One of the primary endpoints in this clinical investigation was the 'evaluation of the function by pain scores'. Each section was scored from 0 to 5 with higher values indicating a more severe impact. For the evaluation of the disability in percent, all available items were used. The mean ODI score decreased significantly from screening with $68 \pm 15.8 \%$ compared to day $6(46 \pm 19.3 \% ; p<0.0001 ; 95 \%$ CI 15.65 , 26.74), month $6(42 \pm 21.9 \% ; p<0.0001 ; 95 \% \mathrm{CI}$ 15.35, 32.72), and month $12(43 \pm 24.5 \%$; $p<0.0001$; 95\% CI 14.3, 30.66). Congruently, the mean pre-post differences (value at post-op visit-screening value) were negative. The decreased mean ODI values after the surgery reflect a decrease of the low back pain disability and thereby an improvement on patients' condition concerning activities of daily living. The decrease of mean ODI score was not significantly different between day 6, month 6, and month 12 .

The pain level was documented using the VAS vertebral spine score. The mean VAS vertebral spine 

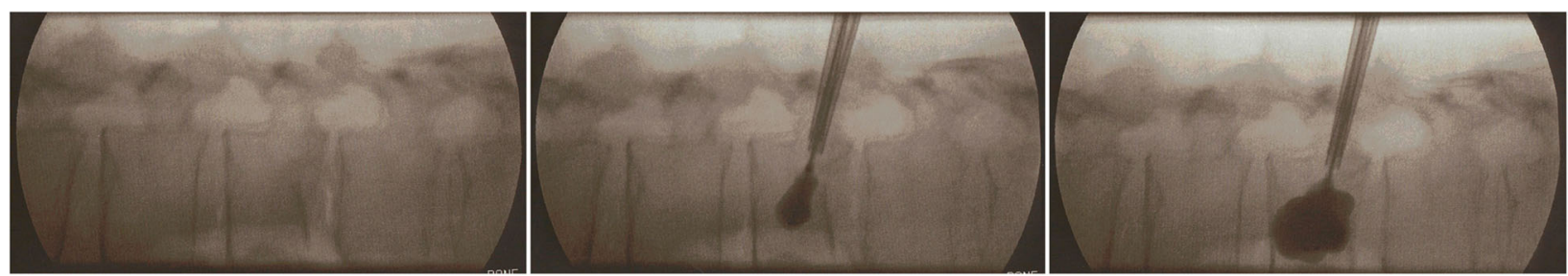

Fig. 1 Kyphoplasty performance using image guidance X-rays. To stabilise and relatively restore the position of the fractured vertebral body ground plate, it was filled with antibiotic-loaded bone cement

score decreased significantly from screening with 68.8 \pm 17.6 to day $6(47.6 \pm 16.8 ; p<0.0001 ; 95 \%$ CI 16 , 25.9), month 6 (43.7 $\pm 20.3 ; p<0.0001 ; 95 \%$ CI 13.85, 29.51), and month $12(43.8 \pm 22.2 ; p<0.0001$; 95\% CI 15.3, 31.4). These results suggest an improvement of the mean pain level after the surgery compared to screening. The decrease of mean VAS vertebral spine score was not significantly different between day 6 , month 6 , and month 12 .

Figure 3 shows the decrease of the low back pain disability as per ODI score. Figure 4 shows an improvement of the mean pain level after the surgery versus the screening as per VAS vertebral spine score.

In addition, an improvement of the general health state over time was shown by increasing the mean values of the SF-36 domain scores (Table 3). The highest increases of the mean value compared to screening were revealed for the domains 'role limitations due to emotional problems' (51.9 \pm 44.7; month 6), followed by 'role limitations due to physical health' (36.1 \pm 42.4 ; month 6$)$, and 'pain' (34.6 \pm 35.3; month 6).

During the clinical study, four patients (8.2\%) experienced at least one adverse event. The documented AEs were chronic obstructive pulmonary disease, transient ischaemic attack, bronchial carcinoma, and death. All documented serious AEs (in three patients, 6.1\%) were assessed as 'not related' to the treatment. Two patients $(4.1 \%)$ died during the course of this study: one died of bronchial carcinoma, the death of the other patient was not further specified. Both fatal adverse events were assessed as serious but had no

Table 1 Assessment of cement properties (safety population (SAF), patients $n=49$ )

\begin{tabular}{|c|c|c|c|}
\hline & $\begin{array}{l}\text { Excellent, } \\
n(\%)\end{array}$ & $\begin{array}{l}\text { Good, } \\
n(\%)\end{array}$ & $\begin{array}{l}\text { Moderate, } \\
n(\%)\end{array}$ \\
\hline Overall assessment & $21(42.9)$ & $\begin{array}{l}28 \\
(57.1)\end{array}$ & \\
\hline $\begin{array}{l}\text { Assessment of cement mixing } \\
\text { procedure }\end{array}$ & $3(6.1)$ & $\begin{array}{l}45 \\
(91.8)\end{array}$ & $1(2)$ \\
\hline
\end{tabular}

relation to the treatment. These cases were documented as discontinuation of the patient.

\section{Discussion}

In this monocentric, open clinical investigation in patients undergoing a one-staged kyphoplasty, the cement properties and benefits regarding application safety were evaluated, using descriptive statistical methods.

\section{Cement properties}

The evaluation results for the primary endpoints 'evaluation of function by pain scores', 'radiological

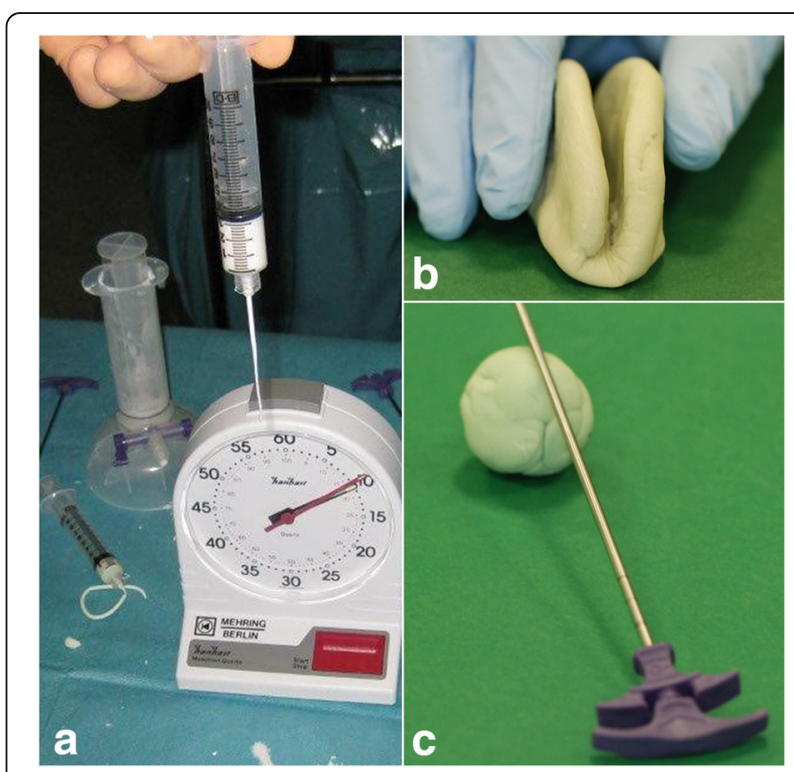

Fig. 2 Monitoring of the cement. a The cement is ready to use when samples are able to form a coherent string of $10 \mathrm{~cm}$ ("drip" test). As soon as the cement does no longer form threads between thumb and forefinger, it can be applied immediately ("thread" test, not shown). $\mathbf{b}$ After that, and as long as folding is possible, plasticity is indicated, although the cement is not fit for usage anymore ("butterfly" test). c It can be assumed that the cement has hardened when contact of the sample with a metal stick provokes a certain sound ("ball" test). A previously prepared, hardened cement can be used as a reference 
Table 2 Evaluation of the timeframes for the cement application

\begin{tabular}{|c|c|c|c|c|}
\hline Application steps & Side & $\begin{array}{l}\text { SAF } \\
\text { number }\end{array}$ & Mean & Min; max \\
\hline \multirow{2}{*}{$\begin{array}{l}\text { Duration of cement } \\
\text { application }\end{array}$} & Left & 49 & $110.74 \mathrm{~s}$ & $30 s ; 250 s$ \\
\hline & Right & 49 & $104.48 \mathrm{~s}$ & $0 \mathrm{~s} ; 250 \mathrm{~s}$ \\
\hline \multirow{2}{*}{$\begin{array}{l}\text { Starting of preparation } \\
\text { time }\end{array}$} & Left & 49 & $29.94 \mathrm{~s}$ & $25 \mathrm{~s} ; 31 \mathrm{~s}$ \\
\hline & Right & 49 & $29.94 \mathrm{~s}$ & $25 \mathrm{~s} ; 31 \mathrm{~s}$ \\
\hline \multirow{2}{*}{$\begin{array}{l}\text { Time of plasticity } \\
\text { without adhesiveness }\end{array}$} & Left & 48 & $6 \mathrm{~min}$ & $4 \mathrm{~min} ; 7 \mathrm{~min}$ \\
\hline & Right & 48 & $6 \mathrm{~min}$ & $4 \mathrm{~min} ; 7 \mathrm{~min}$ \\
\hline \multirow{2}{*}{$\begin{array}{l}\text { Time of removal } \\
\text { of the needle }\end{array}$} & Left & 48 & $17 \mathrm{~min}$ & $10 \mathrm{~min} ; 25 \mathrm{~min}$ \\
\hline & Right & 48 & $17 \mathrm{~min}$ & $10 \mathrm{~min} ; 25 \mathrm{~min}$ \\
\hline \multirow{2}{*}{$\begin{array}{l}\text { Time of plasticity } \\
\text { without miscibility }\end{array}$} & Left & 48 & $12 \mathrm{~min}$ & $9 \mathrm{~min} ; 18 \mathrm{~min}$ \\
\hline & Right & 49 & $12 \mathrm{~min}$ & $9 \mathrm{~min} ; 18 \mathrm{~min}$ \\
\hline \multirow{2}{*}{$\begin{array}{l}\text { Time of loss of } \\
\text { plasticity }\end{array}$} & Left & 48 & 16 min & $10 \mathrm{~min} ; 25 \mathrm{~min}$ \\
\hline & Right & 49 & $16 \mathrm{~min}$ & 10 min; 25 min \\
\hline \multirow{2}{*}{$\begin{array}{l}\text { Only if leakage } \\
\text { during surgery: } \\
\text { time of leakage }\end{array}$} & Left & 0 & & \\
\hline & Right & 1 & $9 \min$ & \\
\hline
\end{tabular}

investigation', and 'cement leakage' revealed overall positive results. After the application of this antibiotic-loaded bone cement, the results suggest an improvement of the mean pain level after the surgery versus the screening. Furthermore, the improvement of the general health state over time as shown by increasing mean values of the SF-36 domain scores was statistically significant.

There was evidence of a decrease of the low back pain disability and thus an improvement of the patients' condition regarding their daily activities.
This, in total, confirms other study results regarding the application of bone cement as safe and efficient in the kyphoplasty setting $[25,26]$.

The radiological investigation indicates an immediate and persisting stabilisation and reconstruction of the fractured vertebral bodies for the monitored study timeframe. Therefore, the applied bone cement revealed benefits in this regard. As a new aspect for bone cement suitable for vertebroplasty and/or kyphoplasty, the viscosity of the investigated material also displayed obvious benefits. This, in particular, refers to a reduced rate of leakage compared to other studies. Prior studies identified that $12.1 \%$ of the vertebral bodies had a bone cement leakage after percutaneous kyphoplasty [27] or the leakage rate was even more than $50 \%$ after vertebral body stenting and balloon kyphoplasties [28]. In this study, cement leakage was only documented for one patient (2\%). This patient had a ventral right-sided cement leakage of $0.6 \mathrm{ccm}$ at surgery and at day 6 . Moreover, the cement used in the investigation showed proper utilisation characteristics and mostly excellent detectability (95.9\% directly post-op) as well as good tolerability [29].

\section{Clinical effects}

Concerning its overall efficacy, no infections were documented during the study for any of the patients. In addition, none of the assessed patients had a revision of the relevant spinal level between day 6 and month 6 as well as day 6 and month 12. After a 1year follow-up period, an improved patient safety may be concluded in combination with the results outlined above. Other than the direct data evaluation of biological, chemical, and physical records throughout a

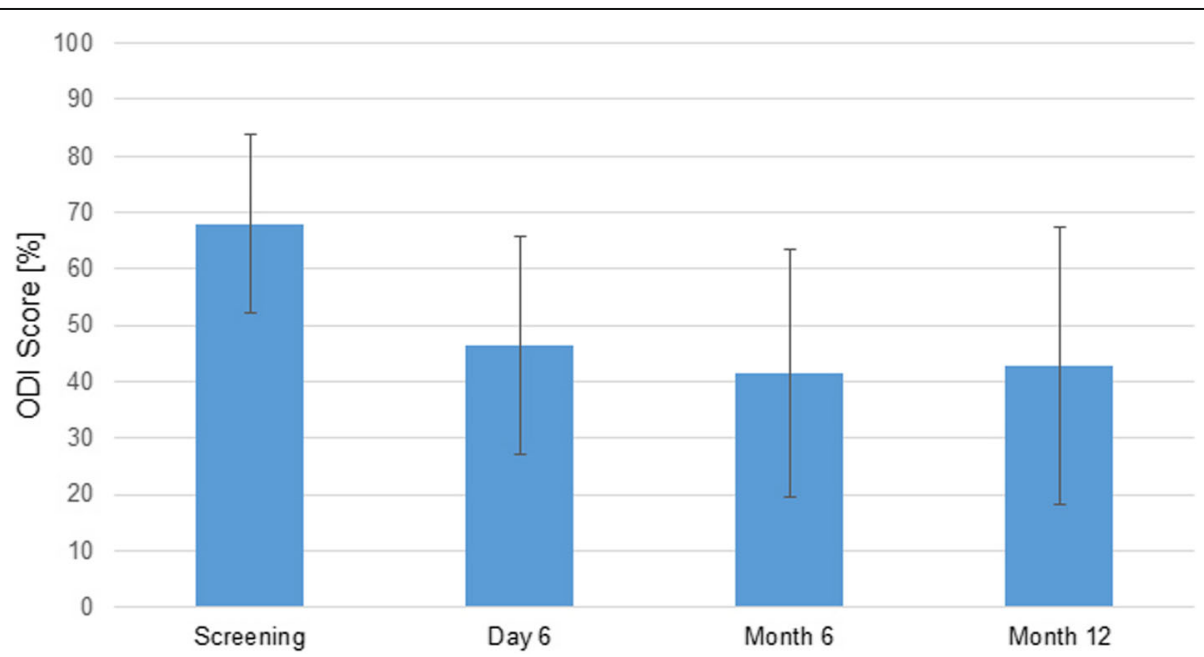

Fig. 3 Summary statistics of the ODI score by visit (SAF, $N=49$ ). Interpretation: 0-20\% minimal disability, 21-40\% moderate disability, 41-60\% severe disability, $61-80 \%$ crippled patients, $81-100 \%$ bed-bound patients or exaggerated symptoms 


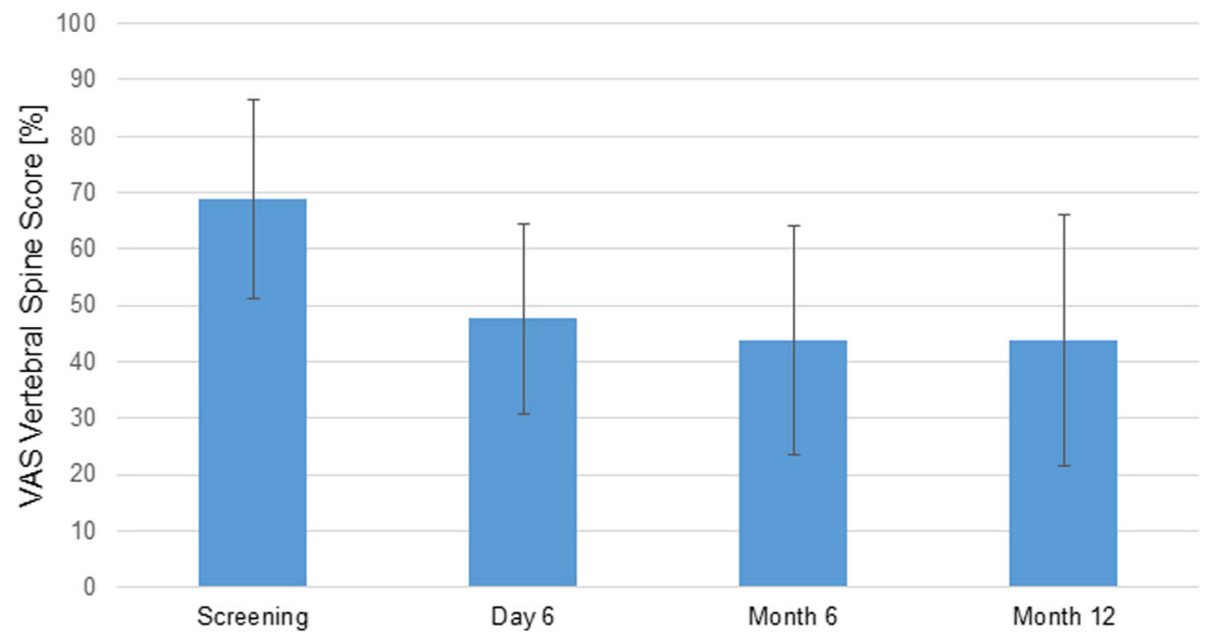

Fig. 4 Summary statistics of the overall VAS vertebral spine score by visit (SAF, $N=49$ ). A lower VAS score indicates lower pain intensity

study conduct the scoring systems, e.g. SF 36, ODI and others revealed some problems. Due to some patients being advanced in years, assistance was required from the clinical staff to understand and fill in the questionnaires. A second problem that can be observed in many studies was the compliance of the patients regarding the follow-up visits.

No clinically relevant abnormality was detected for vital signs at the respective visits and changes from the hospitalisation visit. Furthermore, the safety evaluation raised no safety concerns related to the kyphoplasty treatment of fractured vertebral bodies, and the antibiotic-loaded bone cement was proved to be well tolerated and safe in the evaluated kyphoplasty setting. It would be interesting to see whether the presented study findings could be verified in a larger patient group. More than that, it could be of interest to investigate those findings in a similar surgical procedure in the same field of indication like it is a vertebroplasty.

\section{Safety}

The results of this clinical investigation showed that the kyphoplasty treatment of fractured vertebral bodies with antibiotic-loaded bone cement had a beneficial effect concerning low back pain disability, pain level, general health state of the patients, perioperative infections, and the need for a revision. Thereby, the undesirable effect of the underlying disease on patients' daily life was in general reduced, and it was possible to achieve an improvement on patients' condition over time. An immediate and persisting stabilisation and reconstruction of the fractured vertebral bodies was radiologically confirmed. The applied bone cement revealed proper utilisation characteristics and mainly excellent detectability as well as tolerability. The viscosity of the investigated material indicated benefits regarding a reduced rate of leakage combined with a decreased risk of infection and improved patient safety after a 1-year follow-up period. In addition, cement leakage was only documented for one patient. As an overall assessment of the cement properties for the treatment of fractured vertebral bodies, it can be stated that this bone cement could be worked homogeneously and evenly during kyphoplasty. Therefore, antibiotic-loaded bone cement excellently fulfils the requirements for bone cement in the area of kyphoplasty. The safety evaluation raised no safety concerns related to the kyphoplasty treatment of fractured vertebral bodies with the investigated medical device. It was well tolerated and safe.

\section{Limitations}

The present study used descriptive statistical methods to analyse properties and benefits regarding application safety of an antibiotic-loaded cement in patients undergoing a one-staged kyphoplasty. Since this study is limited to the descriptive analysis of the cement, no control was necessary in this regard. However, the investigated characteristics of the cement can only be compared to results already published in the literature. Thus, in the future, a comparative study will be helpful to directly compare the present cement with other PMMA cements on the market for further validation. 
Table 3 SF-36 domain scores

\begin{tabular}{|c|c|c|c|c|c|}
\hline Parameter & & Screening & Day 6 & Month 6 & Month 12 \\
\hline \multirow[t]{4}{*}{ Physical functioning } & Mean & 16.6 & 34.0 & 39.5 & 37.0 \\
\hline & SD & 20.1 & 21.7 & 26.8 & 28.2 \\
\hline & $p$ value & & 0.0001 & 0.0002 & 0.0053 \\
\hline & $95 \% \mathrm{Cl}$ & & $-25.17 ;-8.9$ & $-31.91 ;-11.46$ & $-29.88 ;-5.64$ \\
\hline \multirow[t]{4}{*}{ Role limitations due to physical health } & Mean & 6.6 & 26.0 & 42.6 & 38.2 \\
\hline & SD & 16.8 & 31.4 & 40.3 & 40.9 \\
\hline & $p$ value & & 0.0001 & 0.0002 & 0.0001 \\
\hline & $95 \% \mathrm{Cl}$ & & $-28.42 ;-10.12$ & $-52.87 ;-19.35$ & $-45.31 ;-16.46$ \\
\hline \multirow[t]{4}{*}{ Role limitations due to emotional problems } & Mean & 10.2 & 25.7 & 56.8 & 50.0 \\
\hline & SD & 27.4 & 40.8 & 42.2 & 45.9 \\
\hline & $p$ value & & 0.0047 & $<0.0001$ & $<0.0001$ \\
\hline & $95 \% \mathrm{Cl}$ & & $-25.65 ;-4.9$ & $-69.52 ;-34.18$ & $-54.73 ;-21.74$ \\
\hline \multirow[t]{4}{*}{ Energy/fatigue } & Mean & 37.2 & 43.0 & 48.9 & 50.3 \\
\hline & SD & 19.4 & 14.7 & 17.7 & 19.2 \\
\hline & $p$ value & & 0.0211 & 0.0227 & 0.0057 \\
\hline & $95 \% \mathrm{Cl}$ & & $-9.92 ;-0.84$ & $-18.48 ;-1.51$ & $-20.28 ;-3.74$ \\
\hline \multirow[t]{4}{*}{ Emotional wellbeing } & Mean & 49.3 & 56.1 & 60.9 & 61.4 \\
\hline & SD & 16.3 & 15.0 & 18.0 & 18.0 \\
\hline & $p$ value & & 0.0098 & 0.0201 & 0.0023 \\
\hline & $95 \% \mathrm{Cl}$ & & $-10.70 ;-1.55$ & $-14.64 ;-1.36$ & $-14.74 ;-3.5$ \\
\hline \multirow[t]{4}{*}{ Social functioning } & Mean & 45.7 & 54.7 & 68.1 & 65.4 \\
\hline & SD & 28.9 & 26.2 & 22.3 & 26.7 \\
\hline & $p$ value & & 0.0036 & 0.0081 & 0.0055 \\
\hline & $95 \% \mathrm{Cl}$ & & $-13.81 ;-2.86$ & $-29.41 ;-4.85$ & $-27.27 ;-5.09$ \\
\hline \multirow[t]{4}{*}{ Pain } & Mean & 19.5 & 28.1 & 55.9 & 54.4 \\
\hline & SD & 19.5 & 22.1 & 25.1 & 23.7 \\
\hline & $p$ value & & 0.0132 & $<0.0001$ & $<0.0001$ \\
\hline & $95 \% \mathrm{Cl}$ & & $-14.66 ;-1.8$ & $-48.99 ;-20.93$ & $-44.23 ;-21.80$ \\
\hline \multirow[t]{4}{*}{ General health } & Mean & 34.3 & 35.6 & 47.4 & 44.7 \\
\hline & SD & 14.5 & 15.8 & 15.0 & 15.8 \\
\hline & $p$ value & & 0.3767 & $<0.0001$ & 0.0001 \\
\hline & $95 \% \mathrm{Cl}$ & & $-4.07 ; 1.57$ & $-18.09 ;-7.84$ & $-16.33 ;-6.02$ \\
\hline
\end{tabular}

\section{Conclusion}

The cement properties of the antibiotic-loaded bone cement applied in this setting has revealed significant benefits regarding the leakage rate, alleviation of pain, and reconstruction of the structure of the vertebral body, as well as an adequate working time with a suitable viscosity for the application of bone cement in the setting of a kyphoplasty. It was possible to confirm the application safety of this investigated medical device. Finally, it may be concluded that the application technique in combination with the cement properties may guarantee the success of the surgery.

\section{Abbreviations}

ALBC: Antibiotic-loaded bone cement; ECG: Electrocardiogram; IMD : Investigational medical product; ODI: Oswestry Low-Back-Pain; OP: Operation; PMMA: Polymethylmethacrylate; SAF: Safety; SD : Standard deviation; SF-36: Short Form-36; VAS: Visual analogue scale

\section{Acknowledgements}

None

Authors' contributions

$\mathrm{MO}$ performed the research and surgery. HB designed the research, analysed the data, and wrote the paper. SV developed the medical device and performed the research. All authors read and approved the final manuscript.

\section{Funding}

This study was funded by Heraeus Medical. The investigated medical device is produced by Heraeus Medical. 


\section{Availability of data and materials}

The datasets used and/or analysed during the current study are available from the corresponding author on reasonable request.

\section{Ethics approval and consent to participate}

The clinical investigation plan (CIP), patient's information sheet and informed consent form, and any other appropriate investigation-related documents were reviewed and approved by an independent ethics committee (IEC) before the start of the clinical investigation 'Ethikkommission der Landesärztekammer Brandenburg', Cottbus, Germany; registration number S19(a)/2009). The investigation was conducted in accordance with good clinical practice (GCP) as required by ISO 14155 guidelines, German Medical Devices Act ('Medizinproduktegesetz'; latest update MPG §\$20-23), Council Directive 93/ 42/EEC, Directive 2007/47/EC, and standard operating procedures (SOPs) for clinical investigation and documentation in force at Heraeus Medical $\mathrm{GmbH}$. Compliance with these requirements also constitutes conformity with the ethical principles of the Declaration of Helsinki.

\section{Consent for publication}

Patients were not required to give informed consent to the study because the analysis used anonymous data that were obtained after each patient agreed to treatment by written consent.

\section{Competing interests}

H. Bosebeck and S. Vogt are employees of Heraeus Medical. There were no conflicts of interest that affected the design and execution of the study protocol or the analysis of the data. M. Opalko does not have any conflict of interest to declare.

\section{Author details}

${ }^{1}$ Klinik für Orthopädie und Unfallchirurgie, Kreiskrankenhaus Prenzlau, Prenzlau, Germany. ${ }^{2}$ Heraeus Medical GmbH, Medical Affairs, Philipp-Reis-Str. 8/13, 61273 Wehrheim, Germany. ${ }^{3}$ Heraeus Medical GmbH, Innovation, Philipp-Reis-Str. 8/13, 61273 Wehrheim, Germany.

Received: 22 November 2018 Accepted: 15 May 2019

Published online: 27 July 2019

\section{References}

1. Landham PR, Baker-Rand HL, Gilbert SJ, Pollintine P, Annesley-Williams DJ, Adams MA, Dolan P. Is kyphoplasty better than vertebroplasty at restoring form and function after severe vertebral wedge fractures? Spine J. 2015;15: 721-2.

2. Armsen N, Boszczyk B. Vertebro-/kyphoplasty history, development, results. Eur J Trauma. 2005:31:433-41.

3. Krüger A, Hierholzer J, Bermann M, Oberkircher L, Buchholtz S. Current status of vertebroblasty and kyphoplasty in Germany: an analysis of surgical disciplines. Unfallchirurg. 2013;116:813-24.

4. Rao RD, Singrakhia MD. Painful osteoporotic vertebral fracture. Pathogenesis, evaluation, and roles of vertebroplasty and kyphoplasty in its management. J Bone Joint Surg Am. 2003;85-A:2010-22.

5. Park SY, Modi HN, Suh SW, Hong JY, Noh W, Yang JH. Epidural cement leakage through pedicle violation after balloon kyphoplasty causing paraparesis in osteoporotic vertebral compression fractures - a report of two cases. J Orthop Surg Res. 2010;5:54.

6. Lee SK, Lee SH, Yoon SP, Lee YT, Jang G, Lim SY, Lee HM, Moon SH, Song KS. Quality of life comparison between vertebroplasty and kyphoplasty in patients with osteoporotic vertebral fractures. Asian Spine J. 2014;8:799-803.

7. Palussière J. The clinical use of Cortoss synthetic bone void filler in the repair of fractures of the vertebral body. In: Szpalski M, Gunzburg R, editors. Vertebral osteoporotic compression fractures. Philadelphia: Lippincott Williams and Wilkins; 2003. p. 151-8.

8. Shin JH, Ha KY, Kim KW, Lee JS, Joo MW. Surgical treatment for delayed pyogenic spondylitis after percutaneous vertebroplasty and kyphoplasty. Report of 4 cases. J Neurosurg Spine. 2008;9:265-72.

9. Summaries of Product Characteristics (SmPC). European Medicines Agency, London. 2015. http://www.medicines.org.uk/emc/medicine/21665. Accessed 18 Feb 2015.

10. Borowski M, Kusz D, Wojciechowski P, Cieliński Ł. Treatment for periprosthetic infection with two-stage revision arthroplasty with a gentamicin loaded spacer. The clinical outcomes. Ortop Traumatol Rehabil. 2012;14:41-54.

11. Yeom JS, Kim WJ, Choy WS, Lee CK, Chang BS, Kang JW. Leakage of cement in percutaneous transpedicular vertebroplasty for painful osteoporotic compression fractures. J Bone Joint Surg Br. 2003;85:83-9.

12. Georgy BA. Clinical experience with high-viscosity cements for percutaneous vertebral body augmentation: occurrence, degree, and location of cement leakage compared with kyphoplasty. AJNR Am J Neuroradiol. 2010;31:504-8.

13. Kühn K-D, Lieb E, Berberich C. PMMA bone cement: what is the role of local antibiotics? Maîtrise Orthopédique. 2016;243:1-15.

14. Kuru P, Akyüz G, Cerşit HP, Çelenlioğlu AE, Cumhur A, Biricik ş, Kozan S, Gökșen A, Özdemir M, Lüleci E. Fracture history in osteoporosis: risk factors and its effect on quality of life. Balkan Med J. 2014;31:295-301.

15. Becker S. The technique of balloon kyphoplasty. In: Becker S, Ogon M, editors. Balloon Kyphoplasty. Wien: Springer-Verlag; 2008. p. 49-71.

16. Dunne NJ, Orr JF. Curing characteristics of acrylic bone cement. J Mater Sci Mater Med. 2002;13:17-22.

17. Baroud G, Samara M, Steffen T. Influence of mixing method on the cement temperature-mixing time history and doughing time of three acrylic cements for vertebroplasty. J Biomed Mater Res B Appl Biomater. 2004;68: $112-6$.

18. Knop C, Oeser M, Bastian L, Lange U, Zdichavsky M, Blauth M. Development and validation of the Visual Analogue Scale (VAS) Spine Score. Unfallchirurg. 2001;104:488-97.

19. Fairbank JC, Couper J, Davies JB, O'Brien JP. The Oswestry low back pain disability questionnaire. Physiotherapy. 1980;66:271-3.

20. Ware JE Jr, Sherbourne CD. The MOS 36-item short-form health survey (SF36). I. Conceptual framework and item selection. Med Care. 1992;30:473-83.

21. Martínez-Maestre MÁ, Corcuera Flores JR, Machuca G, González-Cejudo C, Torrejón R, Castelo-Branco C. Panoramic radiomorphometry and vertebral fractures in Spanish postmenopausal women. Maturitas. 2013;76:364-9.

22. Zolyniak N: Einfluss der Polymerisationstemperatur von Knochenzement auf den Spinalkanal bei der perkutanen Vertebroplastie. MD Thesis, LudwigMaximilians-Universität München. https://edoc.ub.uni-muenchen.de/10827/ (2009). Accessed 18 Feb 2015.

23. Genant HK, Wu CY, van Kuijk C, Nevitt MC. Vertebral fracture assessment using a semiquantitative technique. J Bone Miner Res. 1993;8(9):1137-44.

24. Schnake KJ, Blattert TR, Hahn P, et al. Classification of osteoporotic thoracolumbar spine fractures: recommendations of the Spine Section of the German Society for Orthopaedics and Trauma (DGOU). Global Spine J. 2018;8(2Suppl:46S-9S.

25. Markmiller M. Percutaneous balloon kyphoplasty of malignant lesions of the spine: a prospective consecutive study in 115 patients. Eur Spine J. 2015;24: 2165-72.

26. Joseph RN, Swift AJ, Maliakal PJ. Single centre prospective study of the efficacy of percutaneous cement augmentation in the treatment of vertebral compression fractures. Br J Neurosurg. 2013;27:459-64.

27. Zhao L, Wang L, Wang G, Xu J, Zeng Y, Zheng S, Jiang C, Gui J. Prevention and treatment of bone cement leakage in percutaneous kyphoplasty for osteoporotic vertebral body compression fracture. Zhongguo Xiu Fu Chong Jian Wai Ke Za Zhi. 2009;23:404-7.

28. Capel C, Fichten A, Nicot B, Lefranc M, Toussaint P, Desenclos C, Deramond H, Le Gars D, Peltier J. Should we fear cement leakage during kyphoplasty in percutaneous traumatic spine surgery? A single experience with 76 consecutive cases. Neurochirurgie. 2014;60:293-8.

29. Lewis G. Injectable bone cements for use in vertebroplasty and kyphoplasty: state-of-the-art review. J Biomed Mater Res B Appl Biomater. 2006;76:45668.

\section{Publisher's Note}

Springer Nature remains neutral with regard to jurisdictional claims in published maps and institutional affiliations. 